\title{
Analysis method of cluster perforating tubing strings traffic- ability in horizontal wells for unconventional reservoirs
}

\author{
Xiaoqiang Guo ${ }^{1 *}$, Jun Liu ${ }^{1,2 *}$, Xiang Huang ${ }^{1}$, Zhigang $\mathrm{Du}^{1}$ and Xiao $\mathrm{Li}^{1}$ \\ ${ }^{1}$ School of mechanical and electrical engineering, Southwest Petroleum University, Chengdu Sichuan 610500, China \\ ${ }^{2}$ School of Mechanical Engineering, Chengdu University, Chengdu, 610106, China.
}

\begin{abstract}
The feasibility of a normal perforating operation depends on the perforating tubing string, which is the main component of the cluster perforating tool for the exploration and development of unconventional oil\&gas reservoirs. To improve the efficiency of cluster perforation in horizontal wells, a passing capability analysis model for the tubing string in a wellbore was established, thereby generating complex equations with coefficients that are solved via geometric analyses and the beam-column theory. This model was based on a comprehensive consideration of the friction between the downhole tools and the borehole wall, fluid resistance, wellbore geometric constraint, pump thrust, axial tension, tool variable cross-section, tension of cable head, and tool elastic deformation. Based on field test data, the pass-through capacity of "1 bridge plug + 4 cluster perforating gun string" in the X206 well and the main factors affecting pass-through ability were analyzed to test the validity of the model. The model presented in this paper can provide an effective tool for analyzing the design and operation of a cluster perforating string.
\end{abstract}

\section{Introduction}

In recent years, cluster perforations 1 have resulted in revolutionary developments in perforation technologies 2 . During a cluster perforating operation, the tool string is conveyed to the downhole target stratum via a cable; this is followed by bridge plug setting and multi-cluster perforation 3. As the main component of perforating tools, the cluster perforating string plays an important role during perforating operations. Generally, the length of the tool string can be excessively large. A large tool string can easily get stuck, especially under specific well conditions such as irregular well trajectories and a high dogleg degree. This can result in a sudden rise in the pumping pressure, thereby leading to accidents such as premature setting of a composite bridge plug, deformation of perforated tubing strings, wear failure of tubing-casing and strength failure 5. Hence, more accurate safety evaluation method of cluster perforating tubing strings is urgently needed to ensure the safety of field operation.

There are a wide range of geometric and mechanical methods that can be applied for research on downhole tool pass-through capacity. In the early years, a calculation method for downhole tool pass-through capacity under rigid conditions was proposed 6 . Later, the rigid passthrough capacity model was perfected and a mechanical model for solving the pass-through capacity of downhole tools was established, using the beam-column theory under flexible conditions 7. Based on this, Di et al. 8 considered the influence of a centralizer on the passthrough capacity of the drilling tool, however, the influence of axial force was not be taken into account. Therefore, it is impossible to accurately predict the magnitude of pump thrust at different positions. In 1997, He et al. 9 established a friction calculation model for casing in horizontal wells through mechanical analyses. Subsequently, for the analysis of casing friction, Sui et al. 10 considered the effect of rotating down. In 2008, Wang 11 elaborated on a mechanical analysis method for the downhole tool pass-through capacity. In 2013, Zhu et al. 12 established the control equation for the length of the tool string under rigid conditions. However, as the deformation of the string was not considered, the calculation result was conservative. In 2016, Feng et al. 13 carried out a study on the pass-through capacity of the string under the assumption that the position of the maximum curvature of the borehole trajectory was the sticking point of the multi-layer splitter string, which was an inaccurate assumption.

Currently, for the calculation of downhole tool passthrough capacity, a majority of relevant studies 14 consider the drill tool and pipe as examples and simplify the downhole tool string to an analysis model of the beam with an equal cross section under the transverse component of the net weight and axial pressure. Existing studies also assume that the tool string is stuck at a position of maximum dogleg degree. These models are appropriate for rigid tool strings; however, for tool strings with greater flexibility, including cluster perforating strings, such simplifications and assumptions are significantly different from the actual situation, resulting in a conservative prediction.

\footnotetext{
* Corresponding authors: 786526101@qq.com (Xiaoqiang Guo, PhD)
}

and201031010081@swpu.edu.cn (Jun Liu, PhD, Professor) 
In this study, a pass-through capacity analysis model for a cable pumping cluster perforating string in a wellbore was established, and the field test data was used to verify the effectiveness of the model. The model was based on the comprehensive consideration of factors such as the friction force between the downhole tools and wellbore, wellbore geometry limitation, pump thrust, axial tension, string variable cross section, tension of cable head and tool elastic deformation.

\section{Pass-through capacity analysis model}

\subsection{Determination of well trajectory curvature radius}

The borehole curvature, which describes the degree of curvature of the well trajectory, directly affects the passthrough capacity of downhole tools. The pass-through capacity of downhole tools decreases as the radius of the borehole curvature decreases. Therefore, the method to determine the borehole curvature radius is provided in this study. A section of the well trajectory for any two adjacent measuring points is set as shown in Fig. 117.

It is assumed that the well trajectory has $N$ measuring points and $N+1$ sections. Concurrently, assuming that the sounding increment of the adjacent measuring points section $i$ is $\Delta S$, the increment of the deviation angle is $\Delta \alpha$, and the increment of the azimuth angle is $\Delta \varphi$. Thus, the overall angle change rate (dogleg degree) in section $i$ is $K_{i}$, which is expressed as

$$
K_{i}=\sqrt{\left(\frac{\Delta \alpha}{\Delta S}\right)^{2}+\left(\frac{\Delta \varphi}{\Delta S}\right)^{2} \times \sin ^{2}\left(\frac{\alpha_{i+1}+\alpha_{i}}{2}\right)}
$$

The hole curvature radius in section $i$ is defined as

$$
R_{i}=\frac{1}{K_{i}}
$$

Assuming that the dogleg degree $G_{i}\left({ }^{\circ} / 30 \mathrm{~m}\right)$ in well section $i$ is known, the radius of curvature $R_{i}$ can be expressed as follows:

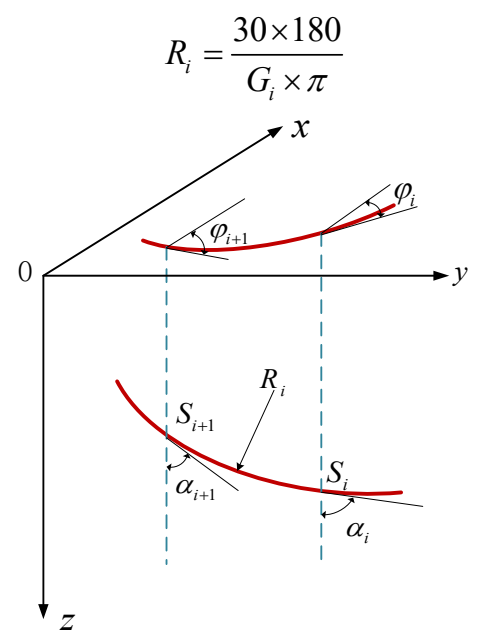

Figure 1. Section of the well trajectory between adjacent measuring points

\subsection{Conditions of string strings passing through wellbore}

As shown in Fig. 4, the hole curvature radius is $R$, wellbore diameter is $d_{\mathrm{b}}$, outside diameter at the midpoint of the perforating string is $d_{\mathrm{z}}$, outside diameter of the bridge plug is $d_{\mathrm{q}}$, total length is $L$, and bending deformation caused by the wellbore constraint in the middle of the string is $y_{\mathrm{c}}$.

According to the geometric relationship shown in Fig. 2, the following can be obtained:

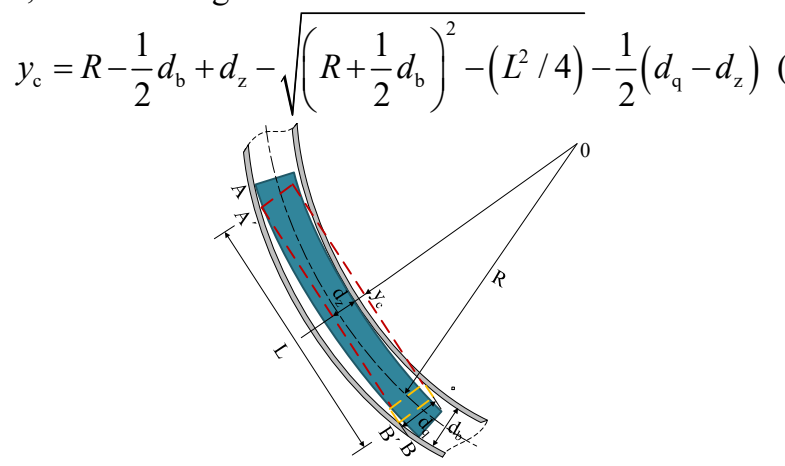

Figure 2. Analysis diagram of pass-through capacity for the cluster perforating tubing strings

The field test indicates that the maximum deflection when running a clustered perforating string occurs near the midpoint of the string. For convenience in the calculation, the midpoint of the tubing string is considered to be the maximum deflection position. The pass-through capacity of the string can be described by the following equations:

Through:

$$
\begin{gathered}
y_{\text {max }} \geq y_{\mathrm{c}} \\
y_{\text {max }}<y_{\mathrm{c}}
\end{gathered}
$$

\subsection{Force and deformation analysis}

According to Eq. (5), and (6), the pass-through capacity of the tubing string is related to the maximum deflection when running, which can be obtained by analyzing the force and deformation of the tubing string.

\section{(1) Force analysis}

For horizontal wells, the friction between the tubing string and inner wall of the wellbore increases as the deviation angle increases. When the tubing string cannot run on its own under the influence of gravity, fluid is generally pumped at the wellhead, forming a differential pressure thrust (pump thrust). This enables the tubing string to smoothly reach the bottom of the well. While running the cluster perforating tool, the axial and transverse force components of the tubing string, total resistance, friction force of the cable, and pump thrust, can be expressed as follows: 


$$
\left\{\begin{array}{l}
F_{\mathrm{p}}=W L \cos \alpha ; F_{\mathrm{n}}=W L \sin \alpha \\
F_{\mathrm{f}}=W L \sin \alpha \cdot f+\frac{1}{2} C_{\mathrm{d}} \rho_{\mathrm{m}} \nu_{\mathrm{r}}^{2} A \\
F_{\mathrm{d}}=W^{\prime} L^{\prime} \sin \alpha \cdot f \\
F_{\mathrm{b}}=W L \sin \alpha \cdot f-W L \cos \alpha+W^{\prime} L^{\prime} \sin \alpha \cdot f
\end{array}\right.
$$

\section{(2) Deformation analysis}

In order to analyze the pass-through capacity of the cluster perforating string in the wellbore, the deformation analysis of the string under various forces in Eq. (7) should be performed.

The concrete cluster perforating tubing string structure is composed of several tools with different lengths and outer diameters. Hence, the calculation of the passthrough capacity is significantly complicated. Therefore, the specific string structure must be simplified to some extent. In this study, part of the string with the same outer diameter is regarded as a section of beam, and the entire cluster perforating string is connected using several sections of the beam with different outer diameters, as shown in Fig. 3. In the process of running, the tubing string is carried by the cable and runs at a relatively stable speed. In this case, the string is affected by the net weight, cable tension, wellbore friction and fluid resistance. This is equivalent to a variable cross section of a simply supported beam under axial tension and transverse distributed load, as shown in Fig. 4.

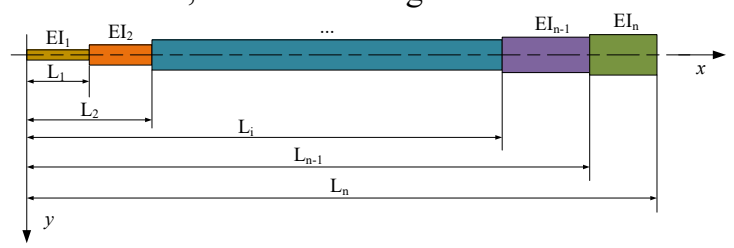

Figure 3. Schematic diagram of the of cluster perforating string structure

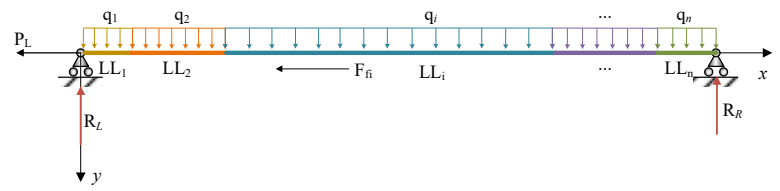

Figure 4. Force analysis diagram of the cluster perforating string

(1) According to the static equilibrium relationship, the reaction force of the two ends of the beam can be obtained, where $q_{i}=W \sin \alpha, L_{0}=0$ :

$$
\left\{\begin{array}{l}
R_{\mathrm{L}}=\frac{\sum_{i=1}^{n} q_{i} L L_{i}\left(L_{5}-L_{i-1}-\frac{1}{2} L L_{i}\right)}{L_{5}} \\
R_{\mathrm{R}}=\frac{\sum_{i=1}^{n} q_{i} L L_{i}\left(L_{i-1}+\frac{1}{2} L L_{i}\right)}{L_{\mathrm{n}}}
\end{array}\right.
$$

(2) Bending moment at any point of the beam can be expressed by:

$$
\begin{aligned}
& \left\{\begin{array}{cc}
M_{1}(x)=R_{\mathrm{L}} x+P_{1} y-\frac{1}{2} q_{1} x^{2} & \left(0 \leq x \leq L_{1}\right) \\
M_{2}(x)=R_{\mathrm{L}} x+P_{2} y-\frac{1}{2} q_{2}\left(x-L_{1}\right)^{2} & \\
-q_{1} L L_{1}\left(x-\frac{1}{2} L L_{1}\right) & \left(L_{1} \leq x \leq L_{2}\right) \\
\vdots &
\end{array}\right. \\
& M_{\mathrm{n}}(x)=R_{\mathrm{L}} x+P_{\mathrm{n}} y-\frac{1}{2} q_{\mathrm{n}}\left(x-L_{\mathrm{n}-1}\right)^{2} \\
& -\sum_{i=1}^{n-1} q_{i} L L_{i}\left(x-L_{i-1}-\frac{1}{2} L L_{i}\right)\left(L_{\mathrm{n}-1} \leq x \leq L_{\mathrm{n}}\right)
\end{aligned}
$$

where $P_{i}(i=1, n)$ is the axial tension in section $i$, and $P_{\mathrm{i}}<0$ is

$$
\left\{\begin{array}{rlr}
P_{i}= & -\frac{1}{2} q_{i} L L_{i} \cos \alpha-\sum_{j=i+1}^{n} q_{j} L L_{j} \cos \alpha & \\
& +q_{i} L L_{i} \sin \alpha \cdot f+\frac{L L_{i}}{2 L_{i}} C_{\mathrm{d}} \rho_{\mathrm{m}} v_{\mathrm{r}}^{2} A \quad(i=1, n-1) \\
P_{\mathrm{n}}= & -\frac{1}{2} q_{\mathrm{n}} L L_{\mathrm{n}} \cos \alpha+q_{\mathrm{n}} L L_{\mathrm{n}} \sin \alpha \cdot f & \\
& +\frac{L L_{\mathrm{n}}}{2 L_{\mathrm{n}}} C_{\mathrm{d}} \rho_{\mathrm{m}} v_{\mathrm{r}}^{2} A & (i=n)
\end{array}\right.
$$

(3) The approximate differential equation for the deflection curve of the beam is

$$
E I_{i} y_{i}^{\prime \prime}=-M_{i}(x) \quad\left(L_{i-1} \leq x \leq L_{i}\right)
$$

(4) The general solution of the differential equation is as follows:

$$
\begin{cases}y_{i}=A_{i} \sin k_{i} x+B_{i} \cos k_{i} x-\frac{N_{i}(x)}{P_{i}}-\frac{E I_{i} q_{i}}{P_{i}^{2}} & \left(L_{i-1} \leq x \leq L_{i}\right) \\ y_{i}^{\prime}=A_{i} k_{i} \cos k_{i} x-B_{i} k_{i} \sin k_{i} x-\frac{N_{i}^{\prime}(x)}{P_{i}} & \left(L_{i-1} \leq x \leq L_{i}\right)\end{cases}
$$

where

$$
\left\{\begin{array}{l}
k_{i}=j \sqrt{\frac{-P_{i}}{E I_{i}}}=j k_{i}^{\prime} ; \sin (j x)=j \operatorname{sh}(x) ; \cos (j x)=\operatorname{ch}(x) ; j=\sqrt{-1} \\
N_{i}(x)=R_{\mathrm{L}} x-\frac{1}{2} q_{i}\left(x-L_{i-1}\right)^{2}-\sum_{j=1}^{i-1} q_{j} L L_{j}\left(x-L_{j-1}-\frac{1}{2} L L_{j}\right) \\
N_{i}^{\prime}(x)=R_{\mathrm{L}}-q_{i}\left(x-L_{i-1}\right)-\sum_{j=1}^{i-1} q_{j} L L_{j}
\end{array}\right.
$$

The deflection and slope equations of the beam determined using Eq. (12) can be further expressed as

$$
\left\{\begin{array}{l}
y_{i}=j A_{i} \operatorname{sh}\left(k_{i}^{\prime} x\right)+B_{i} \operatorname{ch}\left(k_{i}^{\prime} x\right)-\frac{N_{i}(x)}{P_{i}}-\frac{E I_{i} q_{i}}{P_{i}^{2}}\left(L_{i-1} \leq x \leq L_{i}\right) \\
y_{i}^{\prime}=j A_{i} k_{i}^{\prime} \operatorname{ch}\left(k_{i}^{\prime} x\right)+B_{i} k_{i}^{\prime} \operatorname{sh}\left(k_{i}^{\prime} x\right)-\frac{N_{i}^{\prime}(x)}{P_{i}} \quad\left(L_{i-1} \leq x \leq L_{i}\right)
\end{array}\right.
$$

To solve Eq.(11), the corresponding boundary conditions and continuous conditions must also be known. 
The boundary conditions are as follows:

$$
y_{1}(0)=0, y_{\mathrm{n}}\left(L_{\mathrm{n}}\right)=0
$$

In the continuous condition, the deflection and slope at the variable cross section are equal:

$$
\left\{\begin{array}{l}
y_{1}\left(L_{1}\right)=y_{2}\left(L_{1}\right) \\
y_{2}\left(L_{2}\right)=y_{3}\left(L_{2}\right) \\
\cdots \\
y_{\mathrm{n}-1}\left(L_{\mathrm{n}-1}\right)=y_{\mathrm{n}}\left(L_{\mathrm{n}-1}\right)
\end{array},\left\{\begin{array}{l}
y_{1}^{\prime}\left(L_{1}\right)=y_{2}^{\prime}\left(L_{1}\right) \\
y_{2}^{\prime}\left(L_{2}\right)=y_{3}^{\prime}\left(L_{2}\right) \\
\cdots \\
y_{\mathrm{n}-1}{ }^{\prime}\left(L_{\mathrm{n}-1}\right)=y_{\mathrm{n}}{ }^{\prime}\left(L_{\mathrm{n}-1}\right)
\end{array}\right.\right.
$$

\subsection{Solution of the model}

On substituting Eq. (15) and (16) into Eq. (14), the equations of deflection and slope in the matrix form can be expressed as

$$
\boldsymbol{H} \boldsymbol{X}=\boldsymbol{b}
$$

where $\boldsymbol{H}=\boldsymbol{A} \boldsymbol{R}+\boldsymbol{A I} i$ and $\boldsymbol{b}=\boldsymbol{B} \boldsymbol{R}+\boldsymbol{B I} i$ are both complex numbers.

Let $\operatorname{sh}\left(k_{\mathrm{i}}^{\prime} L_{\mathrm{j}}\right)=E_{\mathrm{ij}}^{\prime}, \quad \operatorname{ch}\left(k_{\mathrm{i}}^{\prime} L_{\mathrm{j}}\right)=F_{\mathrm{ij}}^{\prime}(i, j=1, \mathrm{n}) ;$ the terms in Eq. (18) are as follows:

$$
\begin{aligned}
& \boldsymbol{A R}_{2 \mathrm{n} \times 2 \mathrm{n}}=\left(\begin{array}{cccccccccccc}
0 & 1 & 0 & 0 & 0 & 0 & \cdots & 0 & 0 & 0 & 0 & 0 \\
0 & 0 & 0 & 0 & 0 & 0 & \cdots & 0 & 0 & 0 & 0 & F_{\mathrm{nn}}^{\prime} \\
0 & F_{11}^{\prime} & 0 & -F_{21}^{\prime} & 0 & 0 & \cdots & 0 & 0 & 0 & 0 & 0 \\
0 & 0 & 0 & F_{22}^{\prime} & 0 & -F_{32}^{\prime} & \cdots & 0 & 0 & 0 & 0 & 0 \\
\vdots & \vdots & \vdots & \vdots & \vdots & \vdots & & \vdots & \vdots & \vdots & \vdots & \vdots \\
0 & 0 & 0 & 0 & 0 & 0 & \cdots & F_{\mathrm{n}-2, \mathrm{n}-2}^{\prime} & 0 & -F_{\mathrm{n}-1, \mathrm{n}-2}^{\prime} & 0 & 0 \\
0 & 0 & 0 & 0 & 0 & 0 & \cdots & 0 & 0 & F_{\mathrm{n}-1, \mathrm{n}-1}^{\prime} & 0 & -F_{\mathrm{n}, \mathrm{n}-1}^{\prime} \\
0 & k_{1}^{\prime} E_{11}^{\prime} & 0 & -k_{2}^{\prime} E_{21}^{\prime} & 0 & 0 & \cdots & 0 & 0 & 0 & 0 & 0 \\
0 & 0 & 0 & k_{2}^{\prime} E_{22}^{\prime} & 0 & -k_{3}^{\prime} E_{32}^{\prime} & \cdots & 0 & 0 & 0 & 0 & 0 \\
\vdots & \vdots & \vdots & \vdots & \vdots & \vdots & & \vdots & \vdots & \vdots & \vdots & \vdots \\
0 & 0 & 0 & 0 & 0 & 0 & \cdots & k_{n-2}^{\prime} E_{n-2, n-2}^{\prime} & 0 & -k_{n-1}^{\prime} E_{n-1, n-2}^{\prime} & 0 & 0 \\
0 & 0 & 0 & 0 & 0 & 0 & \cdots & 0 & 0 & k_{n-1}^{\prime} E_{n-1, n-1}^{\prime} & 0 & -k_{n}^{\prime} E_{n, n-1}^{\prime}
\end{array}\right) \\
& \boldsymbol{A} \boldsymbol{I}_{2 \mathrm{n} \times 2 \mathrm{n}}=\left(\begin{array}{cccccccccccc}
0 & 0 & 0 & 0 & 0 & \cdots & 0 & 0 & 0 & 0 & 0 & 0 \\
0 & 0 & 0 & 0 & 0 & \cdots & 0 & 0 & 0 & 0 & E_{\mathrm{n}, \mathrm{n}}^{\prime} & 0 \\
E_{11}^{\prime} & 0 & -E_{21}^{\prime} & 0 & 0 & \cdots & 0 & 0 & 0 & 0 & 0 & 0 \\
0 & 0 & E_{22}^{\prime} & 0 & -E_{32}^{\prime} & \cdots & 0 & 0 & 0 & 0 & 0 & 0 \\
\vdots & \vdots & \vdots & \vdots & \vdots & & \vdots & \vdots & \vdots & \vdots & \vdots & \vdots \\
0 & 0 & 0 & 0 & 0 & \cdots & E_{\mathrm{n}-2, \mathrm{n}-2}^{\prime} & 0 & -E_{\mathrm{n}-1, \mathrm{n}-2}^{\prime} & 0 & 0 & 0 \\
0 & 0 & 0 & 0 & 0 & \cdots & 0 & 0 & E_{\mathrm{n}-1, \mathrm{n}-1} & 0 & -E_{\mathrm{n}, \mathrm{n}-1}^{\prime} & 0 \\
k_{1}^{\prime} F_{11}^{\prime} & 0 & -k_{2}^{\prime} F_{21}^{\prime} & 0 & 0 & \cdots & 0 & 0 & 0 & 0 & 0 & 0 \\
0 & 0 & k_{2}^{\prime} F_{22}^{\prime} & 0 & -k_{3}^{\prime} F_{32}^{\prime} & \cdots & 0 & 0 & 0 & 0 & 0 & 0 \\
\vdots & \vdots & \vdots & \vdots & \vdots & & \vdots & \vdots & \vdots & \vdots & \vdots & \vdots \\
0 & 0 & 0 & 0 & 0 & \cdots & k_{\mathrm{n}-2}^{\prime} F_{\mathrm{n}-2, \mathrm{n}-2}^{\prime} & 0 & -k_{\mathrm{n}-1}^{\prime} F_{\mathrm{n}-1, \mathrm{n}-2}^{\prime} & 0 & 0 & 0 \\
0 & 0 & 0 & 0 & 0 & \cdots & 0 & 0 & k_{\mathrm{n}-1}^{\prime} F_{\mathrm{n}-1, \mathrm{n}-1}^{\prime} & 0 & -k_{\mathrm{n}}^{\prime} F_{\mathrm{n}, \mathrm{n}-1}^{\prime} & 0
\end{array}\right)
\end{aligned}
$$

$$
\begin{aligned}
& \boldsymbol{B R}_{2 \mathrm{n} \times 1}=\left(\begin{array}{lllllll}
b_{1} & b_{2} & \cdots & b_{i} & \cdots & b_{2 \mathrm{n}-1} & b_{2 \mathrm{n}}
\end{array}\right)^{\mathrm{T}} \\
& \boldsymbol{B I}_{2 \mathrm{n} \times 1}=0 \\
& \boldsymbol{X}_{2 \mathrm{n} \times 1}=\left(\begin{array}{llllllll}
A_{1} & B_{1} & \cdots & A_{i} & B_{i} & \cdots & A_{\mathrm{n}} & B_{\mathrm{n}}
\end{array}\right)
\end{aligned}
$$

In Eq. (20),

$$
\left\{\begin{array}{c}
b_{1}=\frac{N_{1}(0)}{P_{1}}+\frac{E I_{1} q_{1}}{P_{1}^{2}}, \quad b_{2}=\frac{N_{\mathrm{n}}\left(L_{\mathrm{n}}\right)}{P_{\mathrm{n}}}+\frac{E I_{\mathrm{n}} q_{\mathrm{n}}}{P_{\mathrm{n}}^{2}} \\
\vdots \\
b_{\mathrm{n}+1}=\frac{N_{\mathrm{n}-1}\left(L_{\mathrm{n}-1}\right)}{P_{\mathrm{n}-1}}-\frac{N_{\mathrm{n}}\left(L_{\mathrm{n}-1}\right)}{P_{\mathrm{n}}}+\frac{E I_{\mathrm{n}-1} q_{\mathrm{n}-1}}{P_{\mathrm{n}-1}^{2}}-\frac{E I_{\mathrm{n}} q_{\mathrm{n}}}{P_{\mathrm{n}}^{2}} \\
\vdots \\
b_{2 \mathrm{n}}=\frac{N_{\mathrm{n}-1}^{\prime}\left(L_{\mathrm{n}-1}\right)}{P_{\mathrm{n}-1}}-\frac{N_{\mathrm{n}}{ }^{\prime}\left(L_{\mathrm{n}-1}\right)}{P_{\mathrm{n}}}
\end{array}\right.
$$

The Eq. (17) were solved by the complex coefficient all-selected principal element Gaussian elimination method, and then the Eq. (22) was substituted into the Eq. (14) to obtain the deflection and corner equation of the variable-section simply supported beam. On this basis, the maximum deflection $y_{\max }^{\prime}$ of the string under the situation of no borehole wall constraint can be obtained. In the actual situation of the wall constraint, when $y_{\mathrm{c}}>0$ and $y_{\max }^{\prime} \geq y_{\mathrm{c}}+\left(d_{\mathrm{b}}-d_{\mathrm{w}}\right)$, the maximum deflection $y_{\text {max }}=y_{\mathrm{c}}+\left(d_{\mathrm{b}}-d_{\mathrm{w}}\right)$.

The abovementioned derivation is for the axial force $P_{i}<0$, that is, tension. For horizontal wells, as the string runs, the deviation angle increases and the axial component of the net weight decreases. In this case, the string may be subjected to axial pressure, that is $P_{i}>0$, due to resistance or pump thrust. In this case, $k_{i}$ is replaced 18 by Eq. (24) and substituted into the abovementioned equation to obtain the deflection and slope equation under pressure.

$$
k_{i}=\sqrt{\frac{P_{i}}{E I_{i}}}
$$

The calculation code based on the abovementioned theoretical model is written using the Fortran language, and the procedure shown in Fig. 5. 


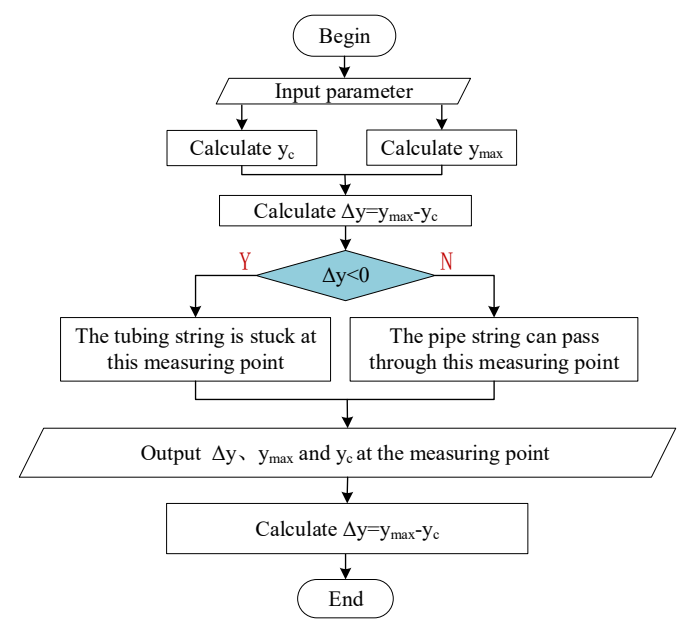

Figure 5. Flow chart of solving model

\section{Results and discussions}

Considering the running of a " 1 bridge plug +4 cluster perforating gun string" in well X206 as an example, a field test of the pass-through capacity of a cable pumping cluster perforating string in a wellbore was performed.

As the measured borehole trajectory parameter is a discontinuous point, the least square method is adopted to fit the actual borehole trajectory data through cubic spline interpolation, to facilitate observation. Starting from the well depth of $3800 \mathrm{~m}$, the measuring points of the borehole trajectory of X206 was fitted. The fitting trajectory is shown in Fig. 6, and the well's inner diameter is $114.3 \mathrm{~mm}$. As can be seen from the borehole trajectory of well X206, it is a typical horizontal well. Moreover, the well depth corresponding to the measuring points is shown in Fig. 7.

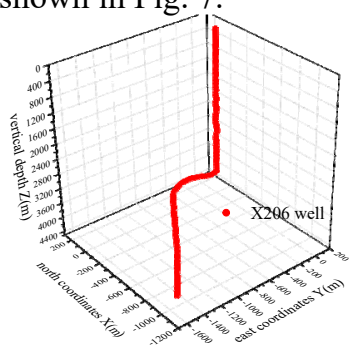

Figure 6. X206 hole trajectory diagram

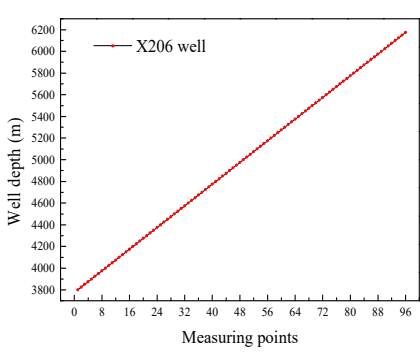

Figure 7. Correlation between measuring points and well depth
The " 1 bridge plug +4 cluster perforating string" run in the X206 well and the perforating tool with the same outer diameter were segmented. The cluster perforating string was divided into 8 sections. The size parameters are shown in Table 1. The relevant calculation parameters are listed in Table 2.

In the field test, the string ran at a relatively stable speed. When the string ran into a well depth of 3800-3900 $\mathrm{m}$, the string exhibited signs of resistance and deceleration, because the section of the well transitioned from the vertical well to the build-up well. The well depth of 3900$4500 \mathrm{~m}$ is termed as the "build-up" section, and the well depth exceeding $4500 \mathrm{~m}$ is termed as the "horizontal" section. When the string runs to a depth of approximately
$4500 \mathrm{~m}$, it is difficult for the string to run under the influence of gravity alone. At this point, the string is run to the bottom of the well by applying pumping thrust.

Subsequently, the pass-through capacity analysis model for the cable pumping cluster perforating string was used to analyze the downhole performance of the "1 bridge plug +4 cluster perforating gun string" in well X206 and compared with the field test results.

Table1. Size parameters of the cluster perforating string

\begin{tabular}{llll}
\hline $\begin{array}{l}\text { Sequence } \\
\text { number }\end{array}$ & $\begin{array}{l}\text { Outer } \\
\text { diameter } / \mathrm{m}\end{array}$ & Volume $/ \mathrm{m}^{3}$ & Length $/ \mathrm{m}$ \\
\hline 1 & 0.043 & 0.00078 & 0.58 \\
2 & 0.073 & 0.00043 & 0.12 \\
3 & 0.083 & 0.01335 & 2.52 \\
4 & 0.089 & 0.01374 & 2.25 \\
5 & 0.073 & 0.00537 & 1.367 \\
6 & 0.089 & 0.02246 & 7.104 \\
7 & 0.099 & 0.00756 & 2.119 \\
8 & 0.103 & 0.00504 & 0.98 \\
\hline
\end{tabular}

Table2. Related parameters of calculation

\begin{tabular}{ll}
\hline Parameters & Value \\
\hline String elastic modulus & $206 \mathrm{GPa}$ \\
String density & $7850 \mathrm{~kg} / \mathrm{m}^{3}$ \\
Cable linear density in well fluid & $230 \mathrm{~kg} / \mathrm{km}$ \\
Well fluid density & $1100 \mathrm{~kg} / \mathrm{m}^{3}$ \\
String down speed & $1.45 \mathrm{~m} / \mathrm{s}$ \\
Friction coefficient & 0.25 \\
Fluid resistance coefficient & 165 \\
\hline
\end{tabular}

\subsection{Situation analysis of string stuck}

During the running process of the string, the net weight and axial tension cause a certain bending deformation. When the maximum deflection $y_{\max }$ is less than the $y_{\mathrm{c}}$ value of the corresponding measuring points, that is, $y_{\text {max }}<y_{\mathrm{c}}$, the string will get stuck. Fig. 8 is a schematic diagram of $y_{\max }$ and $y_{\mathrm{c}}$; it presents the changes in the measuring points when string is run into the X206 well.

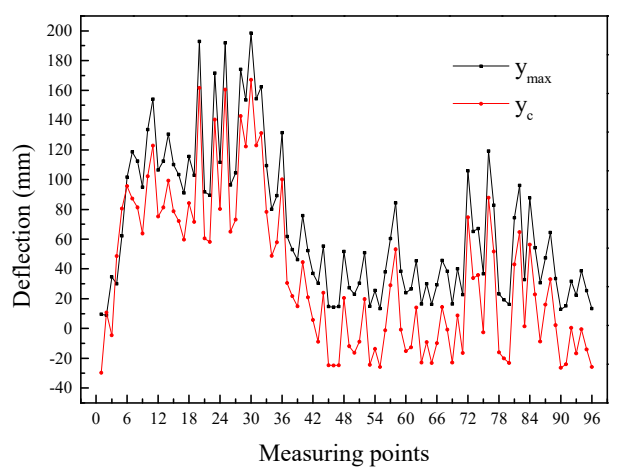

Figure 8. Variation in $y_{\max }$ and $y_{c}$ at different measuring points

In Fig. 8, for the first 6 measuring points, $y_{\max }<y_{\mathrm{c}}$ for three measuring points, and the string was blocked at these positions. This was attributed to the large dogleg 
degree and small deviation angle of the well segment. In the measuring points between 6 and 32, the dogleg degree is large, and the deviation angle increases gradually. Hence, $y_{\max }$ as well as $y_{\mathrm{c}}$ are large. In this case, $y_{\max }>y_{\mathrm{c}}$, and the string will not be blocked. After the string runs through measuring point 32 , the change in $y_{\max }$ and $y_{\mathrm{c}}$ is consistent, and $y_{\mathrm{c}}$ is always less than $y_{\max }$ because the string is close to the inner wall of the wellbore due to net weight deformation in the horizontal section. These observations are consistent with the actual phenomena observed in the field.

\subsection{Analysis of downhole mechanical analysis}

As the string runs, the deviation angle and the resistance to the string increases. When the resistance is greater than the axial component of the net weight of the string, the string will stop running. At this point, the pump thrust is needed to push the string down to the bottom of the well. According to Eq. (7), the string's friction, axial forces and the cable friction force vary with the measuring points while applying the pump thrust, as shown in Fig. 9.

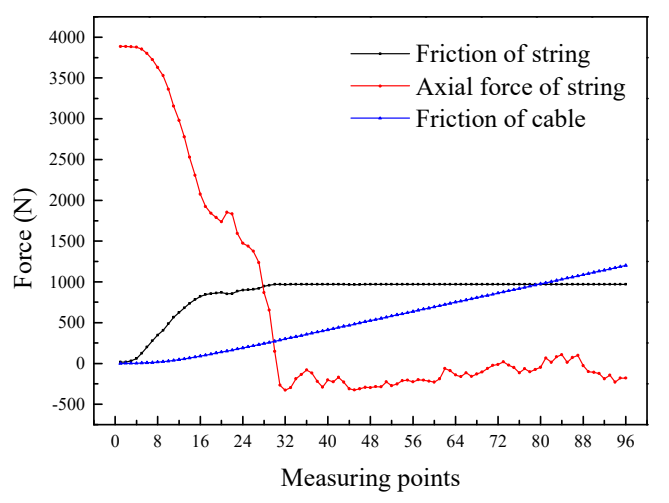

Figure 9. Change in friction and axial force of the string

Observing Fig. 9, the build-up section is between measuring points 1 and 30, and the deviation angle increases gradually, so the axial component of the string decreases, and the friction of the string increases. The horizontal section of the well is after the measuring point of 30 , and the deviation angle fluctuates around $90^{\circ}$. Therefore, the friction of the string changes steadily, and the axial force fluctuates around $0 \mathrm{~N}$. As the downhole cable gradually increases with the downhole string, the friction force generated by the net weight component of the cable increases gradually in the build-up section and the horizontal section. With the combination of Eq. (7) and Fig. 9, the pump thrust can be calculated, as shown in Fig. 10.

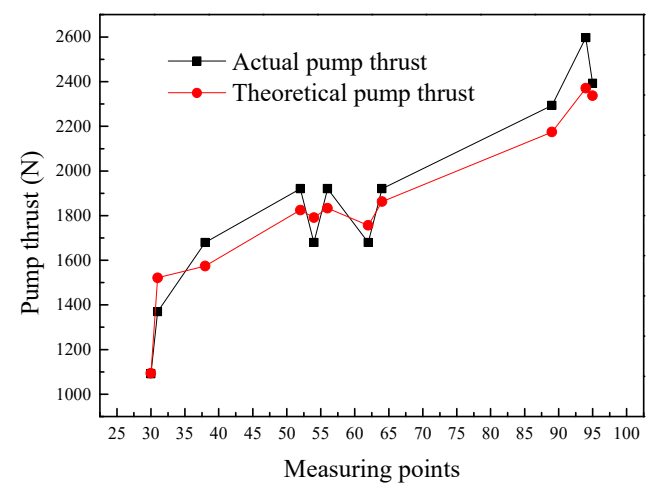

Figure 10. Schematic diagram of the change in pump thrust

Fig. 10 shows that the difference between the calculated and measured pump thrust is small in quantity, and consistent throughout. The main reasons for the difference are due to the fact that the calculation of the pump thrust 19 is relatively complicated, it is not only related to the above various resistances, but also affected by string structure, pumping fluid impact force, the fluid velocity calculation method, and other factors [20].

For general working conditions, if the string can run to the bottom of the well, it can also pass through the wellbore smoothly when pulled up. The difference is that the cable head may be pulled off due to excessive tension, so the cable head should be checked before designing the string. During the process of pulling the string at a relatively stable speed, the tension exerted by the cable head can be expressed as

$$
F_{\mathrm{L}}=W L \cos \alpha+W L \sin \alpha \cdot f+\frac{1}{2} C_{\mathrm{d}} \rho_{\mathrm{m}} \nu_{\mathrm{r}}^{2} A
$$

Combined Eq. (25) with field data, the change of tension of cable head in the pulling can be obtained

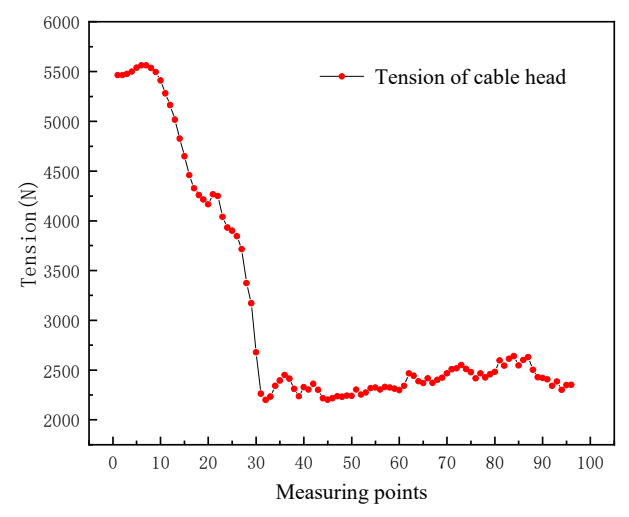

Figure 11. The change of tension of cable head in the pulling

Fig. 11 shows that during the pulling process, the cable head tension was about $2.5 \mathrm{kN}$ in the horizontal section. With the pulling of the string, the deviation angle decreases, the axial component of the string increases, and the cable head tension increases. When the string reached the measuring point $5 \sim 8$, the cable head tension reached the peak value of $5.56 \mathrm{kN}$. In the field test, the peak tension of cable head was between $5 \sim 5.5 \mathrm{kN}$, and the allowable tension was $12 \mathrm{kN}$, so the calculation of cable head tension in this model is close to the reality. 


\section{Conclusions}

(1) Based on a comprehensive consideration of factors such as the friction force between the downhole tools and borehole wall, fluid resistance, wellbore geometric limitation, pump thrust, axial tension, string variable cross section, and tool elastic deformation, a pass-through capability analysis model for a cable pumping cluster perforating string in a wellbore was established. For this model, the geometric analysis method and the beamcolumn theory are mainly used to establish the complex coefficient equations to be solved. According to the continuous and boundary conditions, the pass-through capacity of downhole tools in wellbores with different structures can be solved using the mathematical model and proposed solution method.

(2) On the basis of the field test data, the pass-through capacity of a cluster perforating string and the main factors affecting the pass-through capacity were analyzed. The field data were compared with the model prediction results to verify the effectiveness of the model. Prior to designing and running the string, the analysis model can be used to predict the sticking points of the string and the required pump thrust.

(3) When the string runs through the sticking points, a relaxing cable tension or an acceptable pump thrust is not sufficient to run the string, indicating that the string cannot pass through the well section. Therefore, it should be replaced with a string of smaller outer diameter or a shorter length of string for perforating. In this study, for the calculation of fluid resistance, the values of drag coefficient and the string running velocity were within a certain range. To obtain a more accurate relative velocity and fluid resistance coefficient when running the cluster perforating string, the drag coefficient should be determined through several calibration tests, and the running velocity of the string should be measured at each measuring point

\section{Acknowledgments}

This work has been supported in part by National Natural Science Foundation of China (Grant No. 51875489) and the China Scholarship Council (CSC, File No.201908510191).

\section{Nomenclature}

$\Delta S \quad$ Sounding increment of the adjacent measuring points section $i, \mathrm{~m}$

$\Delta \alpha \quad$ Increment of the deviation angle, $\mathrm{rad}$

$\Delta \varphi \quad$ Increment of the azimuth angle, $\mathrm{rad}$

$K_{i} \quad$ Overall angle change rate in section

$R_{i} \quad$ Hole curvature radius in section $i, \mathrm{~m}$

$G_{i} \quad$ Dogleg degree, ${ }^{\circ} / 30 \mathrm{~m}$

$d_{\mathrm{b}} \quad$ Wellbore diameter, $\mathrm{m}$

$d$ Outside diameter at the midpoint of the perforating string, $\mathrm{m}$ $d_{\mathrm{q}} \quad$ Outside diameter of the bridge plug, $\mathrm{m}$

$L \quad$ Total length of tubing string, $\mathrm{m}$

$y_{c} \quad$ bending deformation caused by the wellbore constraint in the middle of the string, $\mathrm{m}$

$y_{\max } \quad$ Maximum deflection of pipe string, $m$

$F_{\mathrm{p}} \quad$ Axial component of the string, N

$F_{\text {n }} \quad$ Transverse component of the string, N

$F_{\mathrm{f}} \quad$ Total resistance of the string, N

$F_{\mathrm{d}} \quad$ Friction force suffered by the cable, N

$F_{\text {b }} \quad$ Pump thrust, N

$W \quad$ String and cable weight per unit length in well fluid, $\mathrm{N} / \mathrm{m}$

$W^{\prime} \quad$ Cable weight per unit length in well fluid, $\mathrm{N} / \mathrm{m}$;

$L^{\prime} \quad$ Length of cable in deviation section and

$L^{\prime} \quad$ horizontal section, $\mathrm{m}$

$\alpha \quad$ Deviation angle, $\left({ }^{\circ}\right)$

$f \quad$ Friction coefficient between pipe string, cable and wellbore

$C_{\mathrm{d}} \quad$ Fluid resistance coefficient

$v_{\mathrm{r}} \quad$ Corresponding velocity of the string and the well liquid, $\mathrm{m} / \mathrm{s}$

$\rho_{\mathrm{m}} \quad$ Well fluid density, $\mathrm{kg} / \mathrm{m}^{3}$

$A$ Maximum cross-sectional area of the string, $\mathrm{m}^{2}$

$y_{i} \quad$ Deformation deflection in section $i, \mathrm{~m}$

$y_{i}^{\prime} \quad$ Corner in section $i$, rad

$R_{\mathrm{L}} \quad$ Reaction force of the left end of the simplysupported beam, $\mathrm{N}$

$R_{R} \quad$ Reaction force of the right end of the simplysupported beam, $\mathrm{N}$

$L L$ Distance from the variable cross section to the origin of coordinates, $m$

$q_{i} \quad$ Distributed load of section $i$ of beam, N/m

$L_{i} \quad$ Length of section $i$ of beam, m

$P_{\mathrm{L}} \quad$ Cable tension, $\mathrm{N}$

$F_{\mathrm{f} i} \quad$ Friction force on each beam, N

$E \quad$ Elastic modulus of perforating string, $\mathrm{Pa}$

$I_{i} \quad$ Moment of inertia of section $i$ of beam, $\mathrm{m}^{4}$

$P_{i} \quad$ Axial tension at section $i$ of perforating string, $\mathrm{N}$

$F_{\mathrm{L}} \quad$ Cable head tension, $\mathrm{N}$

\section{References}

1. T.X. Jiang, C.G. Jia, H.T. Wang. Shale gas Horizontal Well Sru Fracturing Technology. Beijing: Science Press, 262-265 (2017)

2. H.B. Chen, K. Tang, F. Chen, J.B. Chen, B.C. Li, G.H Ren. Oriented cluster perforating technology and its application in horizontal wells. Natural Gas Industry, 36(07):33-39 (2016)

3. D. Smith, P. Starr. Method to pump bridge/frac plugs at reduced fluid rate//SPE, 13-15 (2008) 
4. C.L. Cipolla, N.R. Warpinskin, M.J. Mayerhofer, E. Lolon, M.C. Vincent. The relationship between fracture complexity, reservoir properties, and fracture treatment design//SPE, 21-24 (2008)

5. D. Vaucher, C. Parrish, R.T. Brooks. Challenges and solutions to running tools through older well completions containing significant paraffin and asphaltene buildup//SPE, 4-5 (2009).

6. J. Ran. Downhole tools in highly deviated fracturing and acidizing wells. Oil Drilling and Production Technology, (02):70-73 (1990)

7. J.P. Zhao, Y.N Su. Drilling tool Assembly passage capacity model and its analysis. Oil Drilling and Production Technology, (05):1-6 (1993)

8. Q.F. Di, Z.Q. Yu. The formulas and analysis of passing-through ability of downhole motor (PTAM). Fault-block Oil \& Gas Field, (04):40-43,48 (1996)

9. S.M. He, X.Y. Guo, Z.H. Wang. Calculation of frictional drag of casing running in horizontal wells. Journal of Southwest Petroleum Institute, (02):2934,4 (1997)

10. M.C. Sui, K.L. Meng, L Du. Analysis of friction on drill string in horizontal drilling. China Petroleum Machinery, (02):9-12,1 (1999)

11. Y.H. Wang. Study on the Tripability of Completion String in Horizontal Well. China University of Petroleum. (2008)

12. X.X. Zhu, S.F. Xue, X.H. Tong. Parameter control methods for the pumping toolstring composed of perforating gun and fracturing plug in a horizontal well. Petroleum Exploration and Development, 40(03):371-376 (2013)

13. D. Feng, L. Shi, C.Y. Xia, H. Zhang, Y.L. Tu. The pass-through capacity analysis for multi-layer injection string in directional wells. Journal of Southwest Petroleum University: Science \& Technology Edition, 38(03):162-169 (2016)

14. Z.X. Chen, X.P. Tang, Z.Q. Gao. Passing ability of medium/short-radius whipstocking screw drill tools inside casing. Oil Drilling and Production Technology, (06):7-10 (1999)

15. Z.J. Wei, J.H. Fu, Y.H. Liu, G. W Zeng. The analysis of PDM with double bent angle running into casing. Fault-block Oil \& Gas Field, (01):68-70,93 (2005)

16. X.H. Zhu, Y. Gao, S.H. Liu, J.M. Xu. Feasibility analysis of single bend screw tripping. Oil Drilling and Production Technology, 33(03):106-108 (2011)

17. C. Qin, X.B. Hu, D.L. Gao. Three-dimensional calculation of sucker rod centralizer spacing in deviated well. China Petroleum Machinery, (05):4548,61 (1997)

18. X.P Tang. Timoshenko beam of variable crosssection (Variablestiffness). Mechanics and Engineering, (04):47-50 (1999)

19. F. Chen, D.B. Yang, X.W. Guo, K. Tang, G.H Ren, Q.B. Zhang. Analysis of pumping process and study of displacement control for static start-up pumping in horizontal section. Well Logging Technology, 42(06):720-725 (2018)

20. F. Chen, D.B.Yang, K. Tang, G.H Ren, Q.B. Zhang, B.C. Li. Pumping multi-cluster perforation and bridge plug joint operation technology for upward inclined wells. Well Logging Technology, 42(01):117-121 (2018) 